\section{Micro-CT Evaluation of Root and Canal Morphology of Mandibular First Premolars with Radicular Grooves}

Emanuele Boschetti ${ }^{1}$, Yara Terezinha Correa Silva-Sousa ${ }^{2}$, Jardel Francisco Mazzi-Chaves' ', Graziela Bianchi Leoni², Marco Aurélio Versiani' ', Jesus Djalma Pécora', Paulo Cesar Saquy', Manoel Damião de Sousa-Neto' ${ }^{1}$

\author{
'Department of Restorative Dentistry, \\ School of Dentistry of Ribeirao \\ Preto, USP - Universidade de São \\ Paulo, Ribeirao Preto, SP, Brazil \\ ${ }^{2}$ Department of Endodontics, \\ School of Dentistry, UNAERP - \\ Universidade de Ribeirão Preto, \\ Ribeirão Preto, SP, Brazil
}

Correspondence: Manoel Damião de Sousa-Neto, Rua Célia de Oliveira Meirelles 350, 14024-070, Ribeirão Preto, SP, Brasil. Tel: +55-16-99912696. e-mail: sousanet@forp.usp.br

\begin{abstract}
The aim of this study was to evaluate morphological features of 70 single-rooted mandibular first premolars with radicular grooves (RG) using micro-CT technology. Teeth were scanned and evaluated regarding the morphology of the roots and root canals as well as length, depth and percentage frequency location of the RG. Volume, surface area and Structure Model Index (SMI) of the canals were measured for the full root length. Two-dimensional parameters and frequency of canal orifices were evaluated at 1, 2, and $3 \mathrm{~mm}$ levels from the apical foramen. The number of accessory canals, the dentinal thickness, and cross-sectional appearance of the canal at different root levels were also recorded. Expression of deep grooves was observed in $21.42 \%$ of the sample. Mean lengths of root and RG were $13.43 \mathrm{~mm}$ and $8.5 \mathrm{~mm}$, respectively, while depth of the RG ranged from 0.75 to $1.13 \mathrm{~mm}$. Mean canal volume, surface area and SMI were $10.78 \mathrm{~mm}^{3}$, $58.51 \mathrm{~mm}^{2}$, and 2.84 , respectively. Apical delta was present in $4.35 \%$ of the sample and accessory canals were observed mostly at the middle and apical thirds. Two-dimensional parameters indicated an oval-shaped cross-sectional appearance of the root canal with a high percentage frequency of canal divisions (87.15\%). Canal configuration type $\mathrm{V}$ $(58.57 \%)$ was the most prevalent. C-shaped configuration was observed in 13 premolars $(18.57 \%)$, whereas dentinal thickness ranged from 1.0 to $1.31 \mathrm{~mm}$. Radicular grooves in mandibular first premolars was associated with the occurrence of several anatomical complexities, including $\mathrm{C}$-shaped canals and divisions of the main root canal.
\end{abstract}

Key Words: bicuspid, dental pulp cavity, endodontics, microcomputed tomography, root canal therapy.

\section{Introduction}

Unsuccessful root canal treatment is mainly caused by failure to recognize variations in root and canal morphologies. Therefore, a thorough knowledge of the morphology of the teeth and an expectation of their likely variations is paramount to minimize endodontic failure caused by incomplete debridement and obturation (1). Previous studies have shown different trends in the shape and number of roots and canals among populations (2-6), which appear to be genetically determined (7-9) and are important for tracing the racial origins of populations.

The presence of developmental depressions in the proximal aspects of the root surface, also referred as radicular grooves (RG) (10), have been demonstrated in different epidemiological studies. Overall, RG is widespread in Africans and native Australians and relatively rare in Western Eurasians $(9,11,12)$. The $R G$ is relevant in clinics as its depth may act as a reservoir for dental plaque and calculus, increasing the difficulty for the management of periodontal disease (13-15). In mandibular premolar teeth, its presence has been associated to anatomical complexities of the root canal system, such as canal bifurcation and C-shaped canal configuration (11,13-18). These complexities are frequently neglected, and the inability to recognize and adequately treat all root canal system helps to explain the highest failure rate in nonsurgical canal therapy of this group of teeth (11.45\%) as previously reported (19).

In spite of root and canal morphologies of the mandibular first premolar teeth have been described is different ethnic groups $(4,6-9,11,15,16,18,20,21)$, literature lacks detailed data on the relationship between $R G$ and root canal morphology in this group of teeth specially in African, Australasian, South East Asian and South American populations. Therefore, the purpose of this study was to evaluate the external and internal morphologies of singlerooted mandibular first premolars with radicular grooves from a Brazilian subpopulation, using micro-CT technology.

\section{Material and Methods}

After local Research Ethics Committee approval (Protocol 0072.0.138.000-09), 500 single-rooted mandibular first premolar teeth from a Brazilian subpopulation were obtained and stored in $0.1 \%$ thymol at $6{ }^{\circ} \mathrm{C}$. The gender and age of the patients were unknown, and all teeth were 
extracted from reasons not related to this study.

Each tooth was slightly dried and examined regarding the number and percentage frequency location of the developing grooves on the external root surface. Scoring of the prevalence and severity of the radicular grooves (RG) was based on the Arizona State University Dental Anthropology Scoring System (ASUDAS) using a standardized reference plaque (22). Teeth categorized as Grades 0 and 1, indicating single-rooted premolars without a development groove or, if present, with a rounded or shallow V-shaped indentations, as well as, Grade 5 (double-rooted premolars), were excluded. As a result, seventy mandibular first premolars $(n=70)$ with fully formed apices were selected and categorized as follows: Grade 2 - developmental groove with a moderately deep $V$-shaped cross-section; Grade 3 - single root with a deep $V$-shaped development groove which extends at least $1 / 3$ of the total root length; and Grade 4 - single root having a deeply invaginated development groove on both the mesial and distal root surfaces. In each sample, the root length was measured as the vertical distance between the lowest level of the cementoenamel junction (CEJ) and the anatomic apex (Fig. 1A), by using a digital caliper with a resolution of $0.01 \mathrm{~mm}$ (Mitutoyo MTI Corporation, Tokyo, Japan).

Each specimen was then imaged separately from the anatomic apex to the crown at an isotropic resolution of $22.9 \mu \mathrm{m}$ (SkyScan 1174v2; Bruker-microCT, Kontich, Belgium). The micro-CT scanner parameters were set at $50 \mathrm{kV}, 800 \mu \mathrm{A}, 180^{\circ}$ rotation around the vertical axis, and rotation step of $1^{\circ}$, using a 0.5 -mm-thick aluminum filter. After the acquired projection images were reconstructed into cross-section slices perpendicular to the long axis of the root (NRecon v.1.6.9 software; Bruker-microCT), polygonal surface representations of the root canals were rendered (CTAn v.1.16 software; Bruker-microCT) and surface modeling (CTVol v.2.3 software; Bruker-microCT).

Each tooth was then resliced perpendicularly at the CEJ plane, at the anatomic apex, at the apical foramen, at the top, middle and bottom levels of the RG, and at 1and 2-mm intervals coronally and/or apically to the CEJ, apical foramen and middle level of the RG, using ImageJ v.1.6.0_24 software (available at www.imagej.nih.gov/ij/) (Fig. 1A). After that, the distances between the CEJ plane, the anatomic apex and the top, middle, and bottom levels of the RG were recorded (Data Viewer v.1.5 software; Bruker-microCT) (Fig. 1B).

Three-dimensional parameters (volume, surface area and Structure Model Index) were measured for the full canal length, while area, roundness, form factor, major and minor diameters, as well as, the percentage frequency of canal orifices, were evaluated at 1,2, and $3 \mathrm{~mm}$ levels from the apical foramen in a coronal direction (CTAn v.1.14.4 software; Bruker-microCT). Detailed descriptions of these parameters were published elsewhere $(23,24)$. The number and location of accessory canals (lateral canals and apical delta) were also recorded. Based on the reconstructed crosssection slices and polygonal 3D models, the configurations of the root canals were classified according to Vertucci's system (1).

The depth of the developmental groove and the dentinal thickness at the deepest point of the RG were measured at the middle level of the $R G$ length $\left(R^{\mathrm{M}}\right)$ and at 1 - and 2-mm intervals coronally and apically to this point (CTAn v.1.16 software; Bruker-microCT) (Fig. 1C). The depth of the $\mathrm{RG}$ was defined as the distance from the deepest point of the groove to the midpoint between the 2 points of tangency at the contour line of the groove (Fig. 1D) (15). For the measurement of the internal and external dentinal thickness, the line traced to measure the groove depth was extended from the deepest point of the groove through the external surface on the other aspect of the root. Then, the distances from the deepest point of the groove to the inner root canal wall, and from the outer root canal wall to the external aspect of the root, were recorded as internal and external dentinal thickness, respectively (Fig. 1E) (14).

Cross-sectional canal shapes of the mandibular first premolars were categorized according to a modified system (13) (Fig. 1F) at the level of the CEJ, apical foramen, middle level of the RG length, as well as, at 1- and 2-mm intervals in the coronal and/or apical directions from these landmarks (Fig. 1A). Then, the number of teeth with $\mathrm{C}$-shaped canals at least in one of the evaluated levels was recorded.

All images were independently and blindly examined on a high-definition computer screen by two experienced evaluators on dental anatomy. Disagreement in the interpretation of the images was discussed until a consensus was reached.

\section{Results}

The incidence of single-rooted mandibular first premolars with developmental grooves grades 2 to 4 was 14\% (70 out of 500 premolar teeth).

\section{External Morphology of the Root}

Mean root length was $13.43 \pm 1.42 \mathrm{~mm}$, while the mean distances between the CEJ and the middle level of the RG, and from this point to the anatomical apex, were $7.36 \mathrm{~mm}$ and $6.07 \mathrm{~mm}$, respectively (Fig. 2). Radicular grooves were present mostly in the mesial aspect of the root (Table 1; Fig. 3A) and expression of deep grooves (ASU 3 and 4) was observed in $21.42 \%$ of the sample $(n=15)$ (Table 1$)$.

\section{Morphology of the Root Canal System}

Table 2 summarizes morphometric data (2D and 3D 
Table 1. Percentage frequency location of radicular grooves and expression of Tomes's trait (ASUDAS system) in 70 single-rooted mandibular first premolars with radicular grooves

\begin{tabular}{|c|c|c|}
\hline Root aspect & \multicolumn{2}{|c|}{$\%(\mathrm{n})$} \\
\hline Mesial & \multicolumn{2}{|c|}{$95.70 \%(\mathrm{n}=67)$} \\
\hline Distal & \multicolumn{2}{|c|}{$2.85 \%(\mathrm{n}=2)$} \\
\hline Vestibular & \multicolumn{2}{|c|}{$1.45 \%(\mathrm{n}=1)$} \\
\hline $\begin{array}{l}\text { ASUDAS } \\
\text { scoring system }\end{array}$ & No Canal Division & Canal Division \\
\hline Grade 2 & $11.42 \%(\mathrm{n}=8)$ & $67.15 \%(\mathrm{n}=47)$ \\
\hline Grade 3 & $1.43 \%(\mathrm{n}=1)$ & $17.15 \%(\mathrm{n}=12)$ \\
\hline Grade 4 & - & $2.85 \%(\mathrm{n}=2)$ \\
\hline
\end{tabular}

Grade 2: developmental groove is present and has a moderately deep V-shaped cross-section; Grade 3: developmental groove is present, V-shaped, and deep. Groove extends at least 1/3 of total root length; Grade 4: developmental grooving is deeply invaginated on both the mesial and distal root surfaces.

Table 2. Morphometric 2D and 3D data (mean \pm standard deviation), as well as, the percentage frequency of canal orifices and number of accessory canals in different root canal levels of 70 mandibular first premolars with radicular grooves

\begin{tabular}{|c|c|c|c|}
\hline 3D parameters & \multicolumn{3}{|c|}{ All canal length (CL) } \\
\hline Volume & \multicolumn{3}{|c|}{$10.78 \pm 5.42 \mathrm{~mm}^{3}$} \\
\hline Surface area & \multicolumn{3}{|c|}{$58.51 \pm 16.41 \mathrm{~mm}^{2}$} \\
\hline Structure Model Index & \multicolumn{3}{|c|}{$2.84 \pm 0.61$} \\
\hline 2D parameters & $\mathrm{CL}-1 \mathrm{~mm}$ & CL - $2 \mathrm{~mm}$ & $\mathrm{CL}-3 \mathrm{~mm}$ \\
\hline Area $\left(\mathrm{mm}^{2}\right)$ & $0.06 \pm 0.10$ & $0.08 \pm 0.14$ & $0.12 \pm 0.22$ \\
\hline Roundness & $0.61 \pm 0.17$ & $0.56 \pm 0.19$ & $0.56 \pm 0.19$ \\
\hline Form factor & $0.80 \pm 0.13$ & $0.76 \pm 0.16$ & $0.75 \pm 0.17$ \\
\hline Major diameter (mm) & $0.34 \pm 0.26$ & $0.41 \pm 0.38$ & $0.48 \pm 0.46$ \\
\hline Minor diameter (mm) & $0.20 \pm 0.10$ & $0.21 \pm 0.13$ & $0.25 \pm 0.16$ \\
\hline Canal orifice(s) (n) & CL $-1 \mathrm{~mm}$ & $\mathrm{CL}-2 \mathrm{~mm}$ & $\mathrm{CL}-3 \mathrm{~mm}$ \\
\hline 1 & $23.2 \%$ & $23.2 \%$ & $21.8 \%$ \\
\hline 2 & $52.2 \%$ & $60.9 \%$ & $63.7 \%$ \\
\hline 3 & $18.8 \%$ & $14.4 \%$ & $13.0 \%$ \\
\hline 4 & $5.8 \%$ & $1.5 \%$ & $1.5 \%$ \\
\hline Accessory canal(s) (n) & $\begin{array}{c}\text { Coronal } \\
\text { third }\end{array}$ & $\begin{array}{c}\text { Middle } \\
\text { third }\end{array}$ & $\begin{array}{c}\text { Apical } \\
\text { third }\end{array}$ \\
\hline 1 & - & 20 & 18 \\
\hline 2 & - & 2 & 14 \\
\hline 3 & - & - & - \\
\hline 4 & - & - & - \\
\hline 5 & - & - & 5 \\
\hline
\end{tabular}

parameters) and the percentage number of canal orifices and accessory canals in various levels of the root. Mean volume and surface area were $10.78 \mathrm{~mm}^{3}$ and $58.51 \mathrm{~mm}^{2}$, respectively. The Structure Model Index (SMI) describes the three-dimensional convexity of the structure (25), i.e. the plate- or cylinder-like geometry of an object. In this study, a mean SMI of 2.84 indicates that the root canal system had a conical frustum-like geometry. Analysis of the area, roundness, and form factor indicated an ovalshaped cross-sectional appearance of the root canal in the apical third. At this same level, the mean major and minor diameters showed an anatomical dimension of the root canal equivalent to a size 35 , taper .06 instrument.

A high percentage frequency of canal divisions was observed $(87.15 \% ; n=61)$ and, in these teeth, the lingual canal after bifurcation was smaller in diameter when compared with the buccal canal (Fig. 3B). At the apical third, a high percentage frequency of 2 canal orifices $(>52 \%)$ was observed, while apical delta was present in only $4.35 \%(n=3)$ of the sample (Fig. 3C). Overall, one or two accessory canals were observed in the middle and apical thirds; however, accessory canals originated from the main canal and exiting at the radicular groove was also observed in $15.9 \%$ of the sample $(n=11)$ (Fig. 3D). Canal configurations types V (1-2 configuration; 58.57\%), I (1-1 configuration; 12.85\%), and III (1-2-1 configuration; $11.43 \%)$ were the most prevalent and additional canal configurations $(n=7 ; 10.0 \%)$ were also observed (Fig. 3E). In two teeth, the canal system could not be classified because of the presence of unanticipated multifurcations and a $\mathrm{C}$-shaped canal at the middle third of the root (Fig. 3F). Overall, C-shaped configuration (Types $\mathrm{C} 1$ and $\mathrm{C} 2$ ) was observed at the level of the RG in 13 premolars $(18.57 \%)$. At the level of the CEJ, teeth usually had only 1 round, oval or flat canal orifice (Types C4a, $4 \mathrm{~b}$ and $4 \mathrm{c}$ ), while in the apical third, most of canal shapes were Types $\mathrm{C} 3$ and $\mathrm{C} 5$.

Table 3. Mean ( \pm standard deviation) dentinal thickness and depth of the RG (in $\mathrm{mm}$ ) measured at the middle level of the full radicular groove length $\left(\mathrm{RG}^{\mathrm{M}}\right)$, and at 1- and 2-mm intervals from this point to the coronal and apical levels

\begin{tabular}{lcccc}
\hline \multirow{2}{*}{$\begin{array}{l}\text { Reference } \\
\text { Level }\end{array}$} & \multicolumn{2}{c}{ Dentinal Thickness } & & Radicular groove \\
\cline { 2 - 3 } \cline { 5 - 5 } & Internal & External & & Depth \\
\hline $\mathrm{RG}^{\mathrm{M}}+2 \mathrm{~mm}$ & $1.31 \pm 0.46$ & $1.31 \pm 0.25$ & & $0.75 \pm 0.47$ \\
$\mathrm{RG}^{\mathrm{M}}+1 \mathrm{~mm}$ & $1.12 \pm 0.38$ & $1.21 \pm 0.25$ & & $1.04 \pm 0.60$ \\
$\mathrm{RG}^{\mathrm{M}}$ & $1.03 \pm 0.30$ & $1.25 \pm 0.24$ & & $1.13 \pm 0.62$ \\
$\mathrm{RG}^{\mathrm{M}}-1 \mathrm{~mm}$ & $1.00 \pm 0.35$ & $1.07 \pm 0.26$ & & $1.01 \pm 0.54$ \\
$\mathrm{RG}^{\mathrm{M}}-2 \mathrm{~mm}$ & $1.00 \pm 0.30$ & $1.02 \pm 0.23$ & & $0.85 \pm 0.44$ \\
\hline
\end{tabular}




\section{Dentinal Thickness}

$R G$ depth varied from 0.75 to $1.13 \mathrm{~mm}$ and was deeper in the cross-section corresponding to the middle point of its full length. The mean dentinal thickness at the middle level of the RG length in either mesial or distal aspects of the root ranged from 1.0 to $1.31 \mathrm{~mm}$ (Table 3).

\section{Discussion}

Successful endodontic treatment of mandibular premolars has been considered difficult to perform because
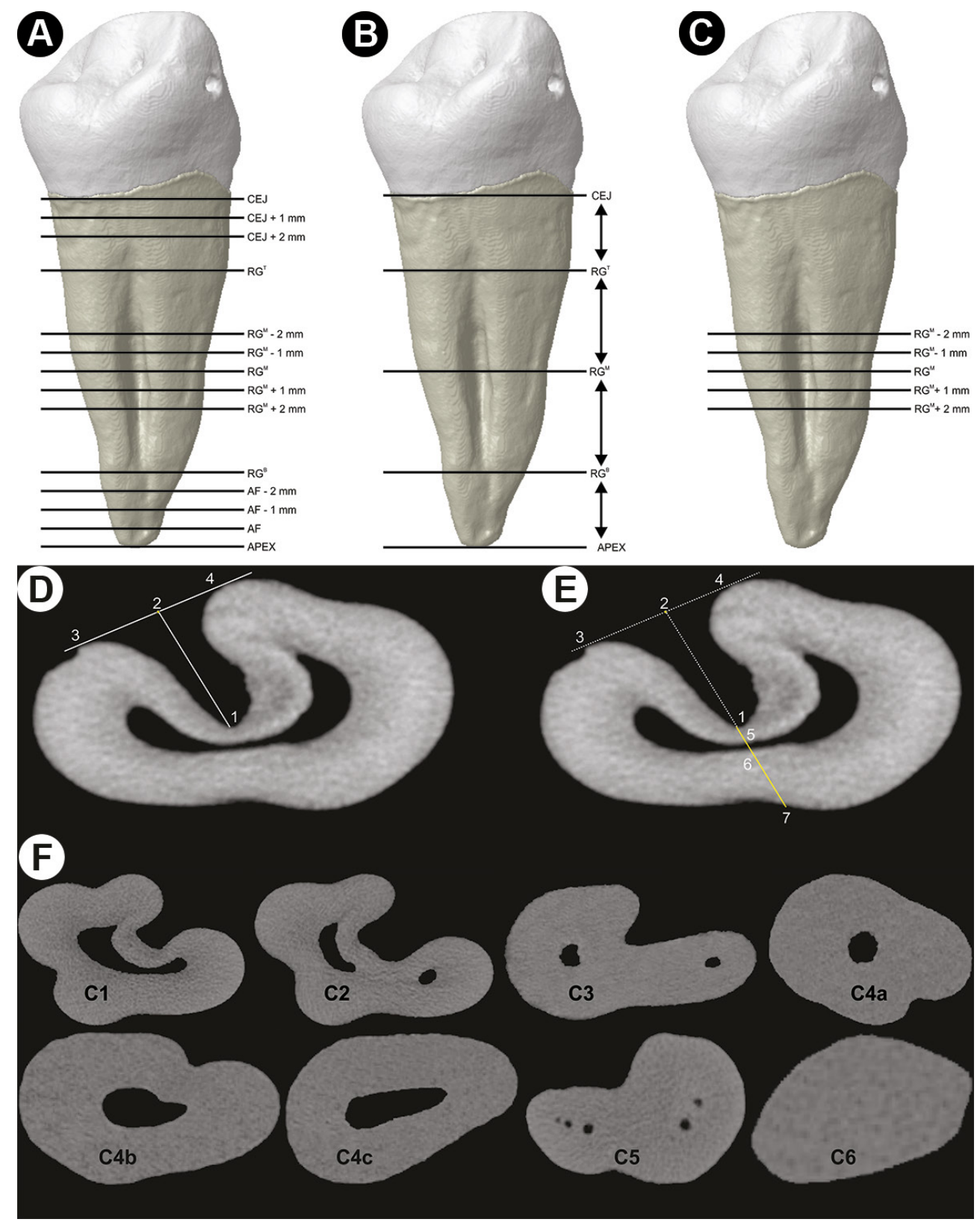

Figure 1. A: The root was digitally resliced perpendicularly at the cementoenamel junction plane (CEJ), at the anatomic apex (APEX), at the apical foramen (AF), at the top $\left(R G^{\mathrm{T}}\right)$, middle $\left(\mathrm{RG}^{\mathrm{M}}\right)$ and bottom $\left(\mathrm{RG}^{\mathrm{B}}\right)$ levels of the groove, and at 1- and 2-mm intervals coronally and/or apically to the CEJ, AF and RGM planes; B: vertical planes measurements between the CEJ plane, the anatomic apex, the top, middle, and bottom levels of the RG were measured; C: measurement levels of the depth of the developmental groove and the dentinal thickness at the middle of the full RG length and at 1- and 2-mm intervals coronally and apically to this point; D: The depth of the RG was defined as the distance from the deepest point of the groove (1) to the midpoint (2) between the 2 tangency points ( 3 and 4) to the contour line of the groove; E: Measurement of the internal and external dentinal thickness were performed from the deepest point of the groove (1) to the inner root canal wall (5), and from the outer root canal wall (6) to the external aspect of the root (7), respectively; F: Cross-sectional canal shapes were categorized into 8 types according to a modified system as $\mathrm{C} 1$ : continuous " $\mathrm{C}$ " with no separation or division; $\mathrm{C} 2$ : canal shape resembled a semicolon resulting from a discontinuation in the "C" outline; C3: 2 separated round, oval, or flat canals; C4: only 1 round, oval, or flat canal in that cross-section (C4a: the long canal diameter almost equal to the short diameter; $\mathrm{C} 4 \mathrm{~b}$ : the long canal diameter was at least 2 times shorter than the short diameter; $\mathrm{C} 4 \mathrm{c}$ : the long canal diameter was at least 2 times longer than the short diameter); C5: 3 or more separate canals in the cross-section; C6: no canal lumen. 
of the numerous variations in root canal morphology usually associated with the presence of developmental root concavities $(9,17,20)$. In the present study, the incidence of RG in mandibular first premolars (14\%) was similar to

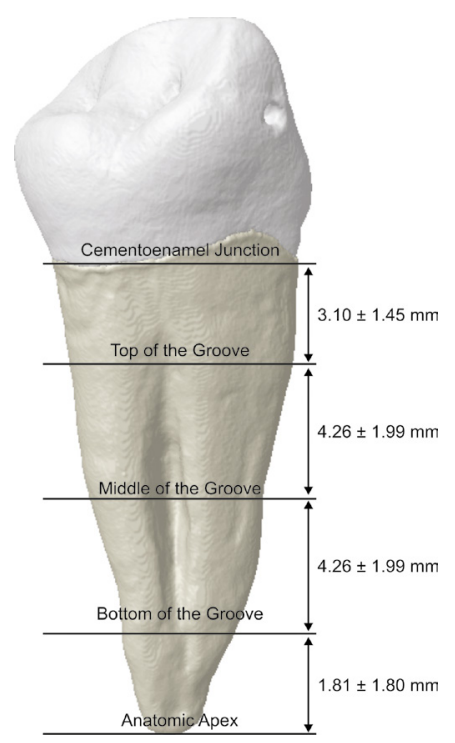

Figure 2. Mean distance, in millimeters, between several anatomical landmarks at the external aspect of the root of mandibular first premolar teeth. that reported by Velmurugan and Sandhya (21), but lower in comparison to the Chinese population (24\% to $27.8 \%$ ) $(13,18)$. This discrepancy has been mostly attributed to racial factors, but also to diversities in sample size, study design, and evaluation method (9). While a common standard has been used for identification of $\mathrm{RG}$, herein, premolar teeth were selected based on the ASUDAS (12), a common standardized tool used in anthropology that allows to set more precisely a threshold between a slight root depression and a typical groove, overcoming the lack of accuracy in sample selection that may have compromised some previous studies. Using this approach, a study in the Chinese population found a higher percentage frequency of deep RG (18.5\%; ASU 3 to 4) (15) than herein (14\%). Although it has been observed variations regarding the point of initiation and depth of RG in mandibular first premolar $(13,18)$, its mean length $(8.5 \mathrm{~mm}$; Fig. 2$)$ and location (95.7\% at the mesial aspect of the root; Table 1) are in accordance to the literature $(13-15,26)$.

The analysis of the morphological features of the root canal system is critical to establish adequate treatment protocols. In this way, micro-CT algorithms allow further measurements of several geometric parameters $(23,24)$, most of them impossible to achieve using conventional methods. Unfortunately, volume, surface area and SMI results (Table 2) cannot be compared to the literature
A
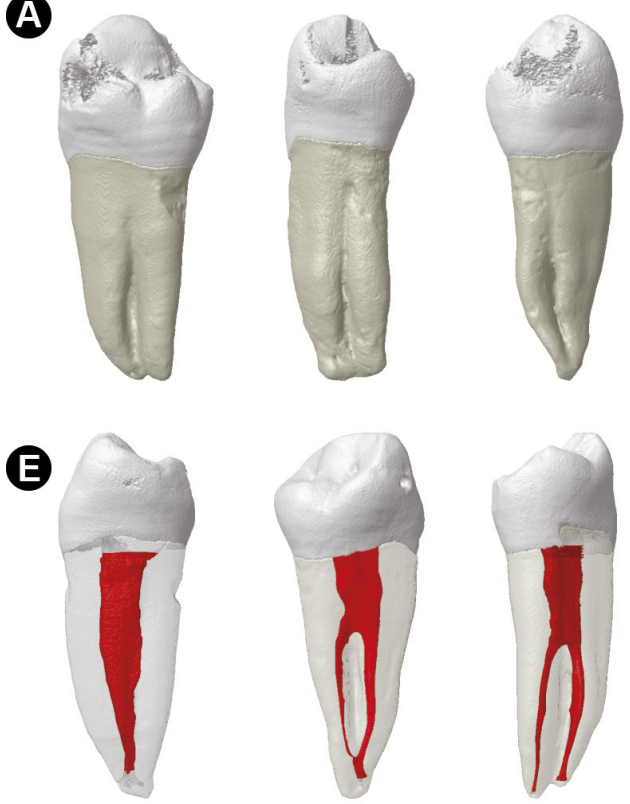

Type I

$12.85 \%(n=9)$

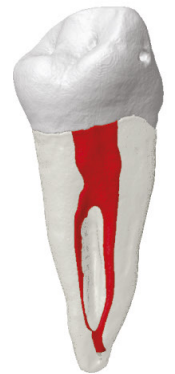

Type III $11.43 \%(n=8)$

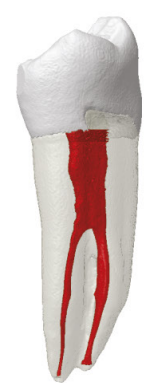

Type V $58.57 \%(n=41)$
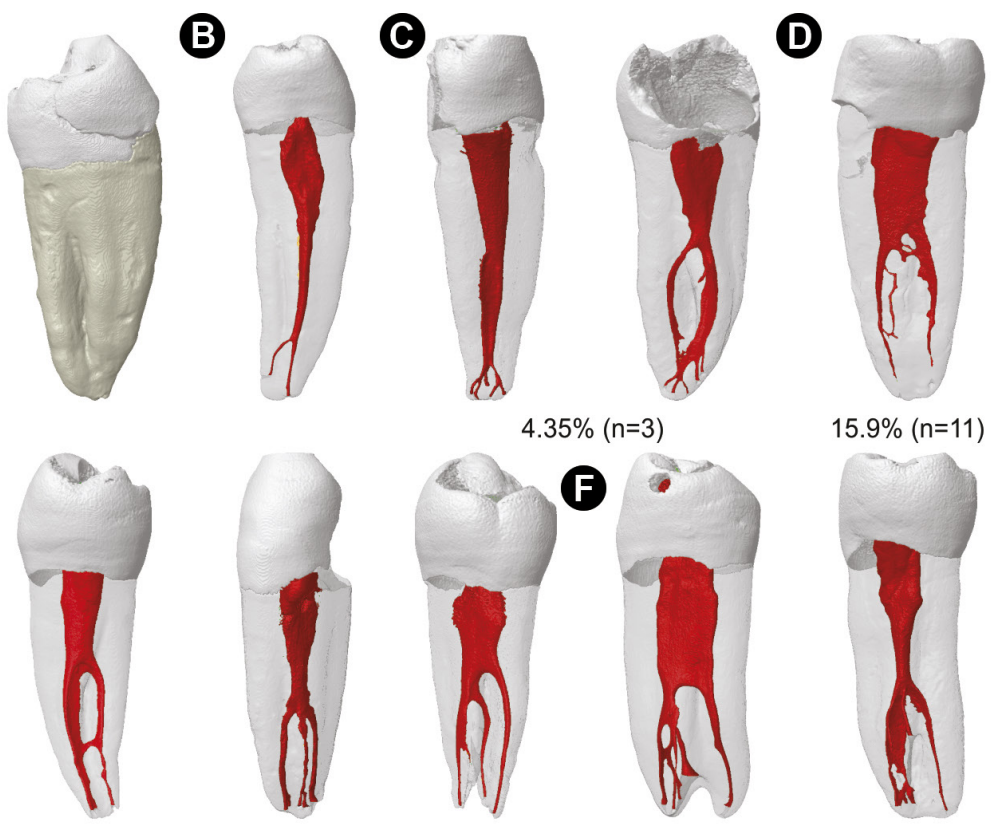

Figure 3. 3D models of mandibular premolars showing A: RG with different depths and lengths in different aspects of the root; B: accessory canals in the apical and middle thirds of the root; C: two premolars with apical delta; D: a premolar with accessory canals originated from the main canal and exiting at the radicular groove; E: the percentage frequency distribution of different root canal configurations observed in mandibular first premolar teeth; F: canal system of 2 premolars showing unanticipated multifurcations and a C-shaped canal at the middle third of the root. 
because no information on this subject was published to date. Despite the clinical relevance of these parameters is still to be determined, they are useful to improve sample selection in further ex vivo experiments (24). In this study, mean thickness of the dentine at the middle level of the $\mathrm{RG}$ varied from 1.0 to $1.31 \mathrm{~mm}$ (Table 3); however, values as low as $0.12 \mathrm{~mm}$ were also observed, in accordance with Gu et al. (14) which have reported thickness of $0.17 \mathrm{~mm}$ in the mesial walls of the developing grooves. Therefore, in this group of teeth, it has been recommended a conservative shaping preparation with small instruments and adequate irrigation to effectively remove tissues from this narrowed space, preventing strip perforation (20).

Evaluation of 2D parameters at the apical third indicated that the debridement at this level could be improved with instruments up to a size 35 , taper .06 (Table 2). However, the cross-sectional appearance of the root canal (roundness and form factor) indicates an oval shape which, combined with multiples orifices, accessory canals, apical delta and a high incidence of C-shaped configuration (Table 2; Fig. 3), could compromise adequate cleaning and shaping procedures $(11,15,16,18)$. Accessory canals were observed in nearly half of the sample $(45.7 \% ; n=32)$, as also reported by $\mathrm{Gu}$ $\vec{s}$ et al. (15) Among these teeth, 37.5\% $(n=12)$ had transverse accessory canals exiting at the deepest invagination of the developmental groove (Fig. 3D). This finding is relevant in clinics because this anatomical structure may allow penetration of bacteria from periodontal pocket into the pulp and vice versa, leading to a pulpitis or persisting periodontitis $(15,17)$. If these anatomic features lead to treatment failure and surgery becomes necessary, these additional structures need to be addressed. Therefore, surgical operative microscope would help clinicians to better visualize the apex $(11,15)$ and thin ultrasonic tips to incorporate the anatomical irregularities, ensuring a proper canal sealing.

Although most of the mandibular premolars have one main root canal, when $R G$ is present, multiple canals with more complex configuration can be observed $(9,17)$. Unfortunately, only a few authors have described the root canal configuration system of mandibular premolar teeth with $R G(15,18,20)$. In these studies, a high incidence of canals types $V(26.4 \%$ to $65.6 \%)$ and I (6.3\% to $15 \%)$ have been reported, in accordance with the present results. On the other hand, type III configuration was also identified in a relatively high percentage of mandibular first premolars (11.43\%) (Fig. 3E).

The main anatomic feature of $\mathrm{C}$-shaped canals is the presence of fins or webs connecting individual canals, which may change the cross-sectional and three-dimensional canal shape along the root (13). Current knowledge derived from micro-CT studies indicated that this ribbon canal space in mandibular first premolars is frequently eccentric to the lingual side of the C-shaped radicular dentin, and that C-shaped canal varies considerably in shape at different levels $(13-15,17,18,20,27)$. In this study, the percentage frequency of C-shaped canals was high (18.57\%), but within the range of $10.7 \%$ to $29 \%$ reported in the literature $(9,11,13,14,16,20,28,29)$. In contrast, a recent micro-CT study reported C-shaped canal configuration in 67\% of the mandibular first premolars with radicular grooves from a Brazilian subpopulation (30). In this study, however, radicular grooves were not classified as herein and it is possible to infer that the selected sample was composed mostly by teeth with deeper grooves, which helps to explain this higher percentage compared to the present results. Besides, in disagreement with a previous study in which a continuous C-shaped canal was observed in more than $16 \%$ of the sample (20), in this study no specimen was found to contain a complete $C$ over the root length.

Many complicating factors make C-shaped canals in mandibular premolars difficult to treat (11) because this configuration is rarely seen in the radiography (15) and its location may hamper its detection from a coronal approach $(11,15)$. All evaluated teeth in this study had only 1 canal orifice at the coronal level (Type C4), while C-shaped canal configuration (Types $\mathrm{C} 1$ and $\mathrm{C} 2$ ) was observed at the middle third, in agreement with previous reports $(14,15)$. Therefore, considering that this anatomical variation in mandibular premolars cannot be easily identify during routine endodontic treatment (15) or by conventional radiography (17), the effect of its shaping and cleaning on the success rate of the endodontic treatment is still to be determined (20).

Despite resolution of the available CBCT devices does not allow for a detailed imaging of fine anatomical structures of the root canal system, this diagnostic tool would be of great help for clinicians in order to identify the presence of RG (31). Considering that mandibular premolar teeth with an associated groove on the external root surface have a high incidence of $\mathrm{C}$-shaped canals and bifurcations $(11,14,15,18,20)$, previous detection of $R G$ would suggest the presence of the anatomical complexities reported herein.

Considering the limitations of the current study, it may be concluded that the incidence of single-rooted mandibular first premolars with developmental grooves from a Brazilian subpopulation was 14\%. Expression of deep grooves (ASU 3 and 4) was observed in $21.42 \%$ of the sample and were associated with a high occurrence of several anatomical complexities, including $\mathrm{C}$-shaped canals and bifurcation.

\section{Resumo}

0 objetivo deste estudo foi avaliar a morfologia de 70 pré-molares inferiores com depressões radiculares (DR) usando a microtomografia. Os 
dentes foram escaneados e avaliados quanto à morfologia das raizes e canais radiculares, bem como o comprimento, profundidade, frequência e localização das DR. 0 volume, a área de superficie e o Structure Model Index (SMI) dos canais foram mensurados no comprimento total da raiz. Parâmetros bidimensionais e orificios do canal foram avaliados a 1,2 e $3 \mathrm{~mm}$ do forame apical. 0 número de canais acessórios, a espessura dentinária e a aparência transversal do canal em diferentes niveis de raiz também foram registrados. A expressão de sulcos profundos foi observada em $21,42 \%$ da amostra. Os comprimentos médios de raiz e DR foram de $13,43 \mathrm{~mm}$ e $8,5 \mathrm{~mm}$, respectivamente, enquanto a profundidade das DR variou de 0,75 a $1,13 \mathrm{~mm}$. 0 volume médio do canal, a área superficial e o SMl foram de $10,78 \mathrm{~mm}^{3}, 58,51 \mathrm{~mm}^{2}$ e 2,84 , respectivamente. 0 delta apical estava presente em $4,35 \%$ da amostra e os canais acessórios foram observados principalmente nos terços médio e apical. Os parâmetros bidimensionais indicaram canais radiculares com secção oval e alta frequência de divisões canal principal $(87,15 \%)$. A configuração Tipo $V$ do canal radicular foi a mais prevalente $(58,57 \%)$. A presença de canais em forma de $C$ foi observada em 13 pré-molares $(18,57 \%)$, enquanto a espessura dentinária variou de 1,0 a $1,31 \mathrm{~mm}$. Os sulcos radiculares nos primeiros pré-molares inferiores foram associados à ocorrência de várias complexidades anatômicas, incluindo canais em forma de $\mathrm{C}$ e múltiplas divisões do canal principal.

\section{References}

1. Vertucci FJ. Root canal morphology and its relationship to endodontic procedures. Endod Topics 2005;10:3-29.

2. Gulabivala K, Aung TH, Alavi A, Ng YL. Root and canal morphology of Burmese mandibular molars. Int Endod J 2001;34:359-370.

3. Gulabivala K, Opasanon A, Ng YL, Alavi A. Root and canal morphology of Thai mandibular molars. Int Endod J 2002;35:56-62.

4. Sert $\mathrm{S}$, Bayirli GS. Evaluation of the root canal configurations of the mandibular and maxillary permanent teeth by gender in the Turkish population. J Endod 2004;30:391-398.

5. Walker RT. Root form and canal anatomy of maxillary first premolars in a southern Chinese population. Endod Dent Traumatol 1987;3:130134.

6. Walker RT. Root canal anatomy of mandibular first premolars in a southern Chinese population. Endod Dent Traumatol 1988;4:226-228.

7. Chaparro AJ, Segura JJ, Guerrero E, Jimenez-Rubio A, Murillo C, Feito $J J$. Number of roots and canals in maxillary first premolars: study of an Andalusian population. Endod Dent Traumatol 1999;15:65-67.

8. Trope M, Elfenbein L, Tronstad L. Mandibular premolars with more than one root canal in different race groups. J Endod 1986;12:343-345.

9. Cleghorn B, Christie W, Dong C. The root and root canal morphology of the human mandibular first premolar: a literature review. J Endod 2007:33:509-516.

10. Tomes CS. A manual of dental anatomy, human and comparative. New York.: MacMillan Co.; 1923. 416 p.

11. Lu TY, Yang SF, Pai SF. Complicated root canal morphology of mandibular first premolar in a Chinese population using the cross section method. J Endod 2006;32:932-936.

12. Scott GR, Turner II CG. The anthropology of modern human teeth: dental morphology and its variation in recent human populations. Cambridge: Cambridge University press; 2000. 382 p.

13. Fan B, Yang J, Gutmann JL, Fan M. Root canal systems in mandibular first premolars with C-shaped root configurations. Part I: Microcomputed tomography mapping of the radicular groove and associated root canal cross-sections. J Endod 2008;34:1337-1341.
14. Gu YC, Zhang YP, Liao ZG, Fei XD. A micro-computed tomographic analysis of wall thickness of $\mathrm{C}$-shaped canals in mandibular first premolars. J Endod 2013;39:973-976.

15. Gu Y, Zhang Y, Liao Z. Root and canal morphology of mandibular first premolars with radicular grooves. Arch Oral Biol 2013;58:1609-1617.

16. Awawdeh LA, Al-Qudah AA. Root form and canal morphology of mandibular premolars in a Jordanian population. Int Endod J 2008:41:240-248.

17. Cleghorn BM, Christie WH, Dong CC. Anomalous mandibular premolars: a mandibular first premolar with three roots and a mandibular second premolar with a C-shaped canal system. Int Endod J 2008;41:10051014.

18. Liu N, Li X, Liu N, Ye L, An J, Nie X, et al. A micro-computed tomography study of the root canal morphology of the mandibular first premolar in a population from southwest China. Clin Oral Investig 2013;19:9991007.

19. Ingle Jl, Bakland LK, Baumgartner G. Endodontics. Hamilton: BC Decker Inc.; 2008. 1527 p.

20. Fan B, Ye B, Xie E, Wu H, Gutmann J. Three-dimensional morphological analysis of $\mathrm{C}$-shaped canals in mandibular first premolars in a Chinese population. Int Endod J 2012;45:1035-1041.

21. Velmurugan N, Sandhya R. Root canal morphology of mandibular first premolars in an Indian population: a laboratory study. Int Endod $J$ 2009;42:54-58.

22. Turner CGII, Nichol CR, Scott GR. Scoring procedures for key morphological Traits of the permanent dentition: The Arizona State University dental anthropology system. In: Kelley MA, Larson CS, editors. Advances in dental anthropology. New York: Wiley-Liss; 1991. p. 13-31.

23. Peters $O A$, Laib $A$, Ruegsegger $P$, Barbakow F. Three-dimensional analysis of root canal geometry by high-resolution computed tomography. J Dent Res 2000;79:1405-1409.

24. Versiani MA, Pécora JD, Sousa-Neto MD. Microcomputed tomography analysis of the root canal morphology of single-rooted mandibular canines. Int Endod J 2013;46:800-807.

25. Hildebrand T, Rüegsegger P. Quantification of bone micro architecture with the structure model index. Comput Methods Biomech Biomed Engin 1997;1:15-23.

26. Woelfel JB, Scheid RC. Dental anatomy: its relevance to dentistry. Philadelphia.: Lippincott Williams \&t Wilkins; 2002. $422 \mathrm{p}$

27. Li $X$, Liu N, Ye L, Nie $X$, Zhou $X$, Wen $X$, et al. A micro-computed tomography study of the location and curvature of the lingual canal in the mandibular first premolar with two canals originating from a single canal. J Endod 2012;38:309-312.

28. Baisden MK, Kulild JC, Weller RN. Root canal configuration of the mandibular first premolar. J Endod 1992;18:505-508.

29. Sikri VK, Sikri P. Mandibular premolars: aberrations in pulp space morphology. Indian J Dent Res 1994;5:9-14.

30. Ordinola-Zapata $R$, Monteiro Bramante $C$, Gagliardi Minotti $P$, Cavalini Cavenago B, Gutmann JL, Moldauer BI, et al. Micro-CT evaluation of C-shaped mandibular first premolars in a Brazilian subpopulation. Int Endod J 2015;48:807-813.

31. Ordinola-Zapata R, Bramante CM, Versiani MA, Moldauer BI, Topham G, Gutmann JL, et al. Comparative accuracy of the Clearing Technique, $\mathrm{CBCT}$ and Micro-CT methods in studying the mesial root canal configuration of mandibular first molars. Int Endod J 2017;50:90-96.

Received August 7, 2017 Accepted October 10, 2017 